\title{
Isolated talonavicular arthrodesis and talonavicular-cuneiform arthrodesis for the Müller-Weiss disease
}

\author{
Hong-hui Cao ${ }^{1}$, Wei-zhong $\mathrm{Lu}^{2}$ and Kang-lai Tang ${ }^{1 *}$ (1)
}

\begin{abstract}
Background: The study aimed to introduce the isolated talonavicular and talonavicular-cuneiform arthrodesis for the stage III and IV Müller-Weiss disease and analyze their clinical outcomes.

Methods: Thirty patients of stage III and IV Müller-Weiss disease were divided into the talonavicular (TN) arthrodesis group and the talonavicular-cuneiform (TNC) arthrodesis group according to the perinavicular osteoarthritis by MRI scans. For the isolated talonavicular arthrodesis group, 16 patients underwent talonavicular arthrodesis with two 4. $0 \mathrm{~mm}$ hollow headless compression screws. For the TNC arthrodesis group, 14 patients were received the TNC arthrodesis with reverse "V" shape osteotomy and autoallergic iliac bone graft. All patients were followed up at 3, 6, 9, and 12 months, and per 6 months after 1 year, by the AOFAS ankle-midfoot scores, and evaluated by radiographic measurements.

Results: All of them were followed up in two groups and all patients were satisfied with their clinical results. At the TN arthrodesis group, the patients' mean was 39.8 months (range, 11-66 months) follow-up. The mean AOFAS ankle and hindfoot scores had improved from $38.3 \pm 5.1$ preoperatively to $88.9 \pm 1.9$ at the last postoperative assessment. At the TNC arthrodesis group, the mean follow-up was 51.7 months (range, 12-90 months). The mean AOFAS ankle and hindfoot scores were $40.1 \pm 7.9$ preoperatively to $90.1 \pm 2.0$ at the last postoperative. All of the cases were solid fusion on the radiograph.

Conclusions: According to MRI evaluation, either TN or TNC arthrodesis for stage III or IV Müller-Weiss disease have the good clinical outcomes with solid fusion rate and obvious improvement of the quality of life of patients.
\end{abstract}

Keywords: Müller-Weiss disease, Autoallergic iliac bone graft, Arthrodesis, Osteotomy

\section{Background}

Müller-Weiss disease is a primary osteonecrosis of the tarsal navicular of unknown etiology [1]. Several theories have been proposed, including primary osteonecrosis [2], traumatic or biomechanical causes, congenital malformation, navicular osteoarthritis [3], and abnormal evolution of Kohler's disease [4], but the delayed ossification of the tarsal navicular and an abnormal force distribution pattern have been the most accepted [5]. Most of the patients complain of chronic dorsomedial midfoot pain on weightbearing midfoot pain resulting in perinavicular osteoarthritis.

\footnotetext{
* Correspondence: tangkanglai@hotmail.com

${ }^{1}$ Department of Orthopaedic Surgery, Southwest Hospital, The Third Military Medical University, Gaotanyan Str. 30, Chongqing 400038, People's Republic of China

Full list of author information is available at the end of the article
}

Maceira [5] classified the patients into five stages according to lateral X-rays: stage 1 shows minimal changes, whereas stage 5 is defined by complete extrusion of the navicular, stages 2-4 showed different degree of the compression of the navicular and the lowering of the longitudinal arch height. But Maceira admitted that the severity of the symptoms may not correspond with the radiological destruction of navicular bone or the stage of the disease.

When prolonged conservative treatment fails, surgery may be indicated. We describe arthrodesis of talonavicular or talonavicular-cuneiform joint according to the perinavicular osteoarthritis by MRI scans for the stage III and IV Müller-Weiss disease. We believe the individualization arthrodesis can restore the length of the medial column 
and relieve the pain caused by removal between the fragments or osteoarthritis.

\section{Methods}

At the isolated talonavicular arthrodesis group, we records 16 patients since 2008 of the Southwest Hospital, Chongqing, China. Sixteen feet in 16 patients $(2$ men and 14 women) with MWD disease were identified. The average age of the patients at the time of surgery was $50.3 \pm 8.4$ years (range, 35 to 62 years). According to the Maceira classifications, there are 11 stage III and 5 stage IV. The compression of the navicular and the severe talonavicular joints arthritis were proved be processing in all cases by MRI (Fig. 1). But none of these patients showed obvious arthritic change in the calcaneocuboid or subtalar joint.

At the TNC group, we recorded 14 patients since 2008 at the same hospital. There involved 14 patients (4 men and 10 women) with the stage III MWD disease. The average age of the patients at the time of surgery was 49.2 years (range, 32 to 69 years). All patients complained of midfoot pain on standing and walking and had gradually collapsed of the medical longitudinal arch, with the arthritic change of talonavicular-cuneiform joint by MRI (Fig. 2).

In both groups, the patients were treated conservatively with insoles and physiotherapy for at least 6 months. None of them had trauma history, rheumatoid arthritis, renal failure, or lupus erythematosus. The patient, who accompanied with multiple arthritis or infection, obvious deformity in hindfoot, was excluded.

\section{The surgical technique}

For the isolated talonavicular arthrodesis group, all patients underwent surgical intervention by the two senior authors (HH Cao and KL Tang) in our hospital. After

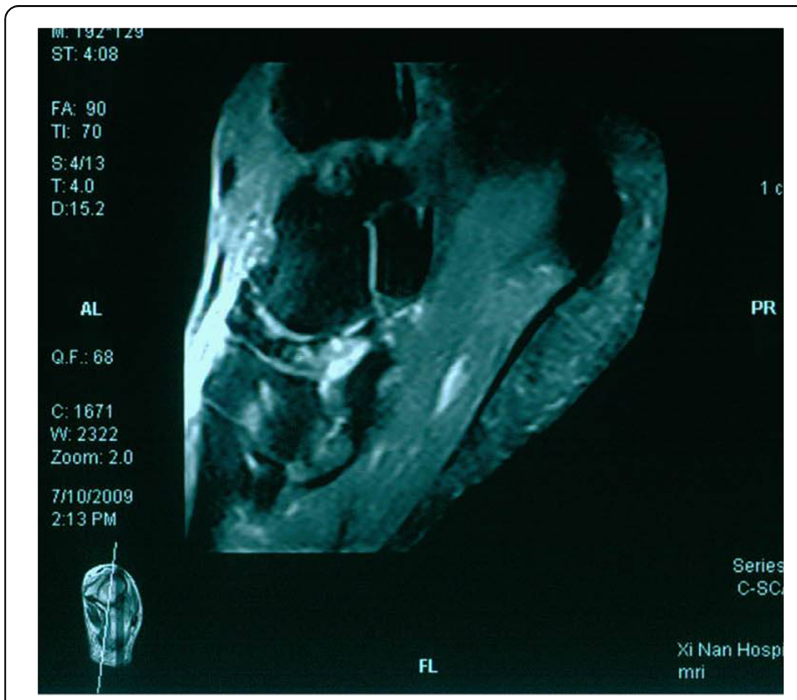

Fig. 1 The necrosis of navicular and severe talonavicular joints arthritis in T2 fast-suppressed image of MRI scans

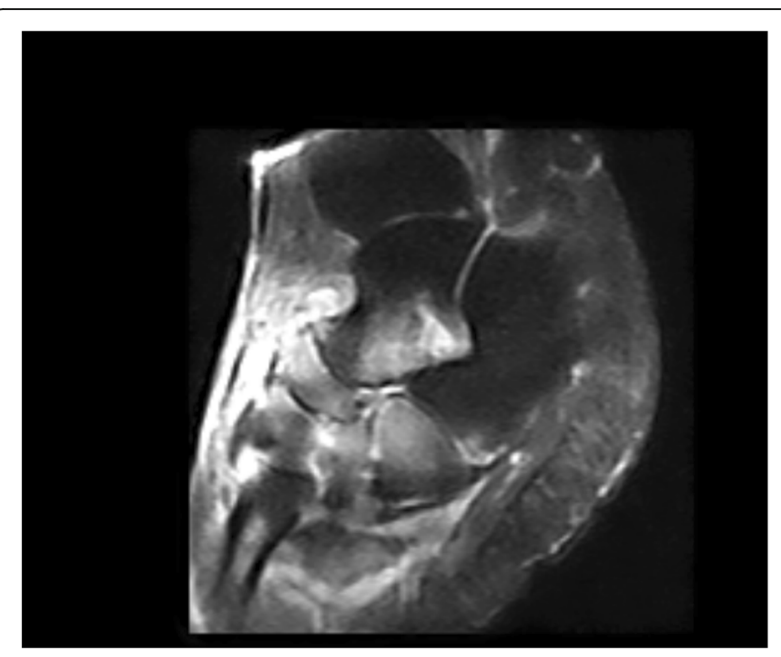

Fig. 2 Magnetic resonance manifest osteonecrosis of the tarsal navicular bone and severe peri-navicular osteoarthritic changes in T2 fast-suppressed image

general anesthesia, the procedure was performed in the supine position with a thigh tourniquet to stanch bleeding. An incision of about $4 \mathrm{~cm}$ was made between the anterior tibial tendon and the extensor hallucis longus to expose the talonavicular joint. The dorsolateral protruding necrotic navicular bone was excised and all residual cartilage was removed from the talonavicular joint. For the stage III cases, two $4.0 \mathrm{~mm}$ hollow headless compression screws (Newdeal, USA) were implanted through the talonavicular joint by vertically the articular surfaces (Fig. 3). The reverse "V" shape osteotomy of talonavicular joint to restore the medial arch height and autoallergic iliac bone graft were applied additionally for the stage IV cases.

For the TNC arthrodesis group, the Prof. Tang performed all operations as the former description by us [6]. After removed the cartilage of the talonavicularcuneiform articular surfaces, the talonavicular joint was osteotomied by reversed "V" shape to restore the height of medial longitudinal arch (Fig. 4a). And then, an about $3 \mathrm{~cm} \times 1.5 \mathrm{~cm} \times 0.5 \mathrm{~cm}$ rectangle bed is carved on the dorsal side of talonavicular-cuneiform. A tricortical autogenous graft of same size and shape as above described is obtained from the iliac crest and is inserted in the practiced bed with the aid of plantarflexion of the foot (Fig. 4b). Two or three cannulated titanium screws of $4.0 \mathrm{~mm}$ (Newdeal, USA) were implanted through the autogenous iliac bone into the triple bones across the talonavicular-cuneiform fusion interface (Fig. 5).

Fluoroscopic control was used throughout to ensure optimal placement of the hardware in the two groups.

\section{Postoperative management and evaluation}

At the end of the surgery, a short leg cast was applied postoperatively for 6 weeks. The negative pressure wound 


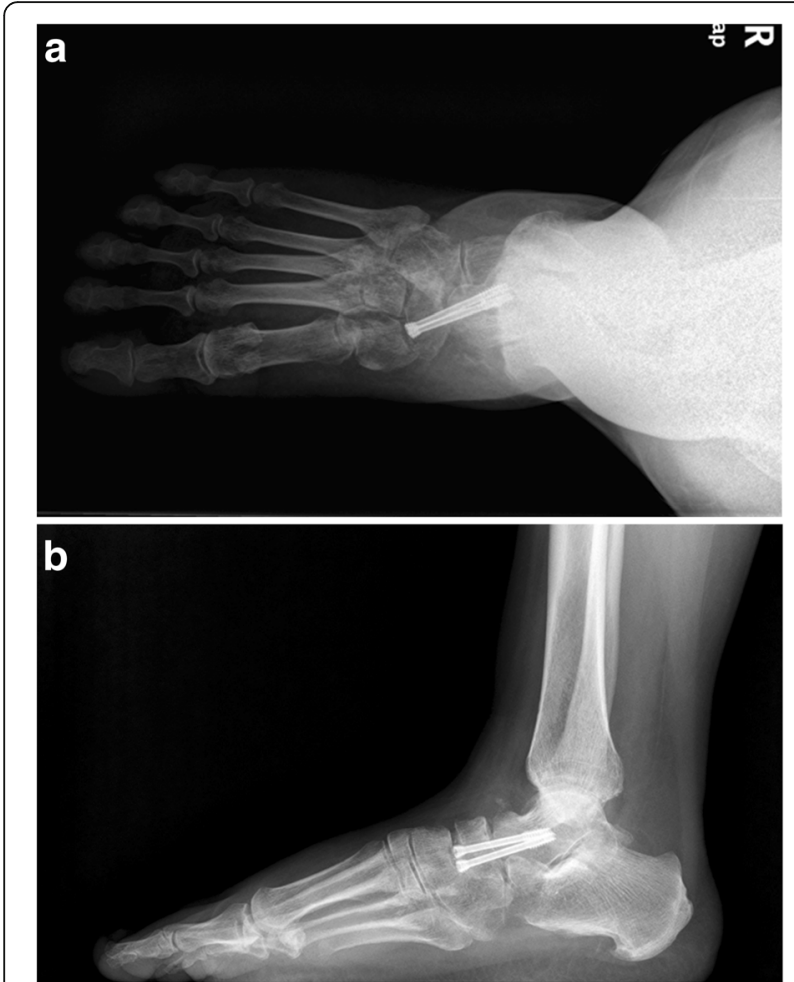

Fig. 3 a, b Two $4.0 \mathrm{~mm}$ hollow headless compression screws were implanted through the talonavicular joint by vertically the articular surfaces
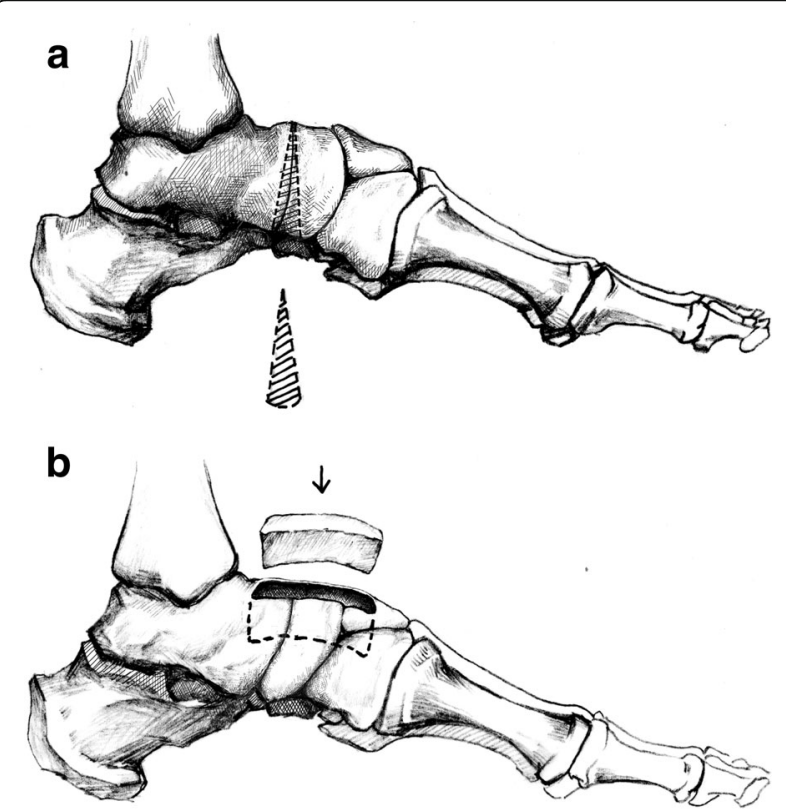

Fig. 4 a, b The talonavicular joint was osteotomied by reversed " $\mathrm{V}$ " shape to restore the height of medial longitudinal arch (a). A tricortical autogenous graft was inserted in the rectangle bed which was carved on the dorsal side of talonavicular-cuneiform (b)

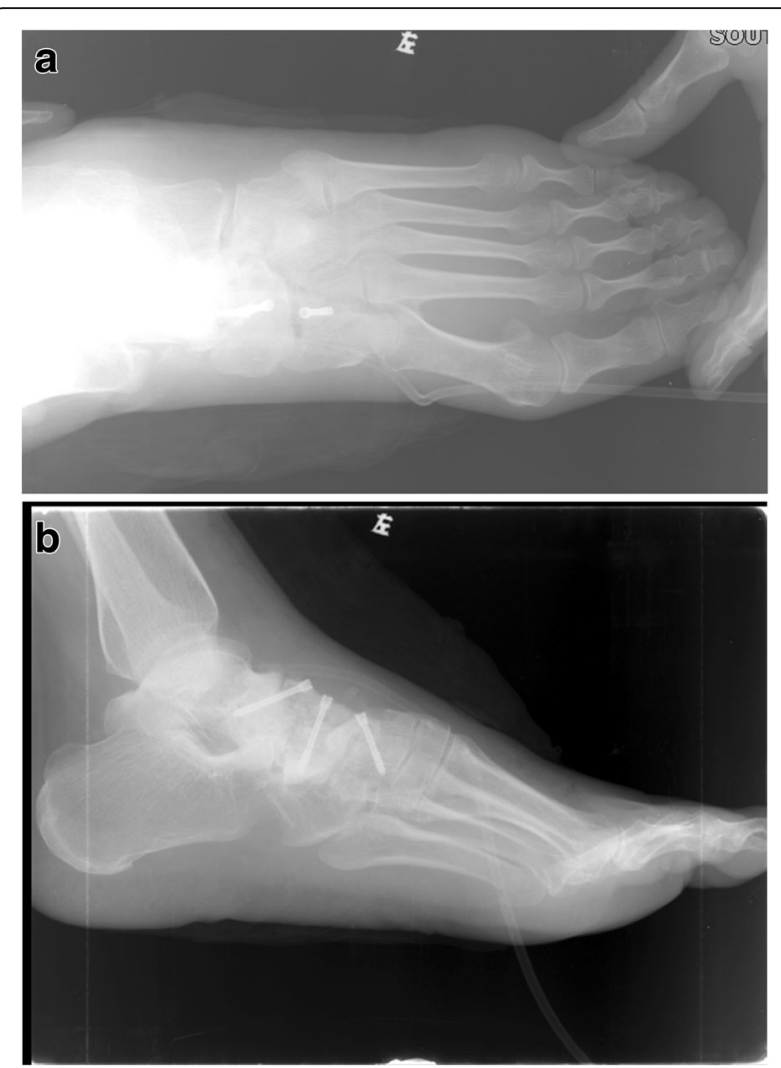

Fig. 5 a, b Three cannulated titanium screws of $4.0 \mathrm{~mm}$ were implanted through the autogenous iliac bone into the triple bones across the talonavicular-cuneiform fusion interface

drainage tube was removed within $48-72 \mathrm{~h}$. Gradual protected weight bearing was allowed 6 weeks after surgery; walk with full weight bearing 3 months after surgery following radiographic evidence of consolidation.

The lateral and AP weight-bearing radiographs of foot were measured for evaluating the bone healing. All patients were evaluated pre-operatively, at 3, 6, 9, and 12 months, and per 6 months after 1 year by clinical examination with AOFAS ankle-hindfoot scores. The protocol of the foot pain, onset and deformity, and complications in or after surgery, were recorded exactly.

All the data was treated with SPSS 13.0, independent sample paired $t$ test, and definite statistical difference as $p<0.05$, significant statistical difference as $p<0.01$.

\section{Results}

All of them were followed up in two groups: $16 \mathrm{TN}$ arthrodesis [age at the intervention, 50.3 years (range, 35-60years); follow-up, 39.8 months (range, 11-66 months); Maceira classifications, 12 stage III and 4 stage IV and 14 TNC arthrodesis [age at intervention, 49.2 years (range, 32-69 years); follow-up 51.7 months (range, 12-90 months); Maceira classifications, 14 stage III] (NS on all items between the two groups). 
All patients were satisfied with their clinical results and were able to walk long distances 6 months after surgery in two groups. Only four patients in TNC arthrodesis complained the slight pain after long distance walking and can be ceased after rest or oral antiinflammatory medication. The mean AOFAS ankle and hindfoot scores had improved from $38.1 \pm 5.0$ preoperatively to $88.1 \pm 2.7$ at the last postoperative assessment in the TN arthrodesis group (Table 1) and the TNC arthrodesis group is $40.1 \pm 7.7$ preoperatively to $90.2 \pm 2.0$ at the last postoperative (Table 2). All of two groups were significantly different between preoperative and postoperative. There is nothing significantly different between the two groups at the last postoperative assessment.

Radiographically, All the operated feet fused solidly at 3 or 6 months after surgery without screw break or loosening; 9/16 in the TN arthrodesis group and 7/14 in the TNC arthrodesis group have removed the inter fixation (Figs. 6 and 7). All the operated feet fused solidly at 3 or 6 months after surgery without screw break or loosening. These results revealed improvements in terms of pain and mobility obtained by these surgical procedures.

\section{Discussion}

Müller-Weiss disease is primary osteonecrosis of the tarsal navicular bone in adult and a rare pathology of unclear etiology in middle age population [1]. The diagnosis of MWD can usually be made with plain radiographs. Maceira [5] further describes the disease by developing a five-stage classification system using lateral weightbearing radiograph, showing a progressive collapse of the medial arch and compression and splitting of the tarsal navicular. It should be distinguished from Köhler's disease [4], which occurs osteochondrosis of the tarsal navicular in children, and from secondary to systemic diseases (rheumatoid arthritis, SLE, renal failure, diabetes) or trauma [7].

It was reported that the therapy of MWD disease was described in the different stage [8]. For early MWD (stage I or stage II) with symptoms, initial conservative therapy includes ankle foot orthoses and oral antiinflammatory medication. If conservative treatment failure, simple excision or drilling decompression is enough [9]. For moderate stage MWD (stage III or stage IV), isolated talonavicular arthrodesis and talonavicularcuneiform (TNC) arthrodesis were reliable. MWD (stage $\mathrm{V}$ ) with marked deformity, the surgical treatment should be double fusion or triple arthrodesis [8-10]. There is no gold standard surgical technique that is effective and safe for the treatment of MWD disease. But early diagnosis and proper treatment are essential for patients' recovery [7]. Traditionally, the standard tools for the diagnosis of MWD disease and judgment of the stage are weightbearing plain radiographs of the foot. But it is difficult to show the minimal changes of adjacent joints. MRI scans may show loss of signal intensity of the navicular on theT1-weighted images and hyperintense diffuse marrow edema and periarticular fluid on the T2weighted images [11]. In these two groups, we choose the isolated talonavicular arthrodesis and talonavicular-

Table 1 Demographic description of the TN Arthrodesis patients

\begin{tabular}{|c|c|c|c|c|c|c|c|c|}
\hline \multirow{2}{*}{$\begin{array}{l}\text { Patient } \\
\text { No }\end{array}$} & \multirow[t]{2}{*}{ Sex } & \multirow[t]{2}{*}{ Age } & \multirow[t]{2}{*}{ Stage } & \multirow[t]{2}{*}{ Side } & \multirow{2}{*}{$\begin{array}{l}\text { Bone } \\
\text { graft }\end{array}$} & \multirow[t]{2}{*}{ Osteotomy } & \multicolumn{2}{|l|}{ AOFAS Score } \\
\hline & & & & & & & Preoperatively & Postoperatively \\
\hline 1 & $\mathrm{~F}$ & 39 & III & Left & no & no & 35 & 80 \\
\hline 2 & $M$ & 39 & III & Left & no & no & 37 & 89 \\
\hline 3 & $\mathrm{~F}$ & 58 & III & Left & no & no & 33 & 88 \\
\hline 4 & $\mathrm{~F}$ & 54 & III & Left & no & no & 39 & 90 \\
\hline 5 & $M$ & 52 & III & Left & no & no & 32 & 90 \\
\hline 6 & $\mathrm{~F}$ & 41 & IV & Left & yes & yes & 39 & 87 \\
\hline 7 & $\mathrm{~F}$ & 60 & IV & Left & yes & yes & 34 & 89 \\
\hline 8 & $\mathrm{~F}$ & 57 & III & Left & no & no & 33 & 82 \\
\hline 9 & $\mathrm{~F}$ & 44 & III & Left & no & no & 47 & 87 \\
\hline 10 & $\mathrm{~F}$ & 62 & IV & Left & yes & yes & 35 & 90 \\
\hline 11 & $\mathrm{~F}$ & 50 & III & Left & no & no & 32 & 95 \\
\hline 12 & $\mathrm{~F}$ & 35 & III & Left & no & no & 55 & 89 \\
\hline 13 & $F$ & 69 & IV & Left & yes & yes & 41 & 92 \\
\hline 14 & $F$ & 37 & III & Left & no & no & 47 & 90 \\
\hline 15 & $\mathrm{~F}$ & 58 & IV & Right & yes & yes & 35 & 87 \\
\hline 16 & $\mathrm{~F}$ & 50 & III & Right & no & no & 35 & 84 \\
\hline Mean & - & $50.3 \pm 8.4$ & - & - & - & - & $38.1 \pm 5.0$ & $88.1 \pm 2.7$ \\
\hline
\end{tabular}


Table 2 Demographic description of the TNC Arthrodesis patients

\begin{tabular}{|c|c|c|c|c|c|c|}
\hline \multirow{2}{*}{$\begin{array}{l}\text { Patient } \\
\text { No }\end{array}$} & \multirow[t]{2}{*}{ Sex } & \multirow[t]{2}{*}{ Age } & \multirow[t]{2}{*}{ Stage } & \multirow[t]{2}{*}{ Side } & \multicolumn{2}{|l|}{ AOFAS Score } \\
\hline & & & & & Preoperatively & Postoperatively \\
\hline 1 & $\mathrm{~F}$ & 46 & III & Left & 55 & 92 \\
\hline 2 & $\mathrm{~F}$ & 52 & III & Right & 49 & 94 \\
\hline 3 & $\mathrm{~F}$ & 41 & III & Right & 26 & 88 \\
\hline 4 & M & 58 & III & Left & 27 & 90 \\
\hline 5 & $\mathrm{~F}$ & 49 & III & Left & 32 & 86 \\
\hline 6 & $\mathrm{~F}$ & 37 & III & Left & 50 & 87 \\
\hline 7 & $\mathrm{~F}$ & 60 & III & Left & 34 & 89 \\
\hline 8 & M & 47 & III & Left & 44 & 89 \\
\hline 9 & M & 32 & III & Right & 44 & 90 \\
\hline 10 & $\mathrm{~F}$ & 62 & III & Left & 32 & 95 \\
\hline 11 & $\mathrm{~F}$ & 34 & III & Left & 50 & 89 \\
\hline 12 & $\mathrm{~F}$ & 50 & III & Right & 38 & 92 \\
\hline 13 & $\mathrm{~F}$ & 69 & III & Left & 40 & 90 \\
\hline 14 & M & 52 & III & Left & 35 & 82 \\
\hline mean & - & $49.2 \pm 8.4$ & - & - & $40.1 \pm 7.7$ & $90.2 \pm 2.0$ \\
\hline
\end{tabular}
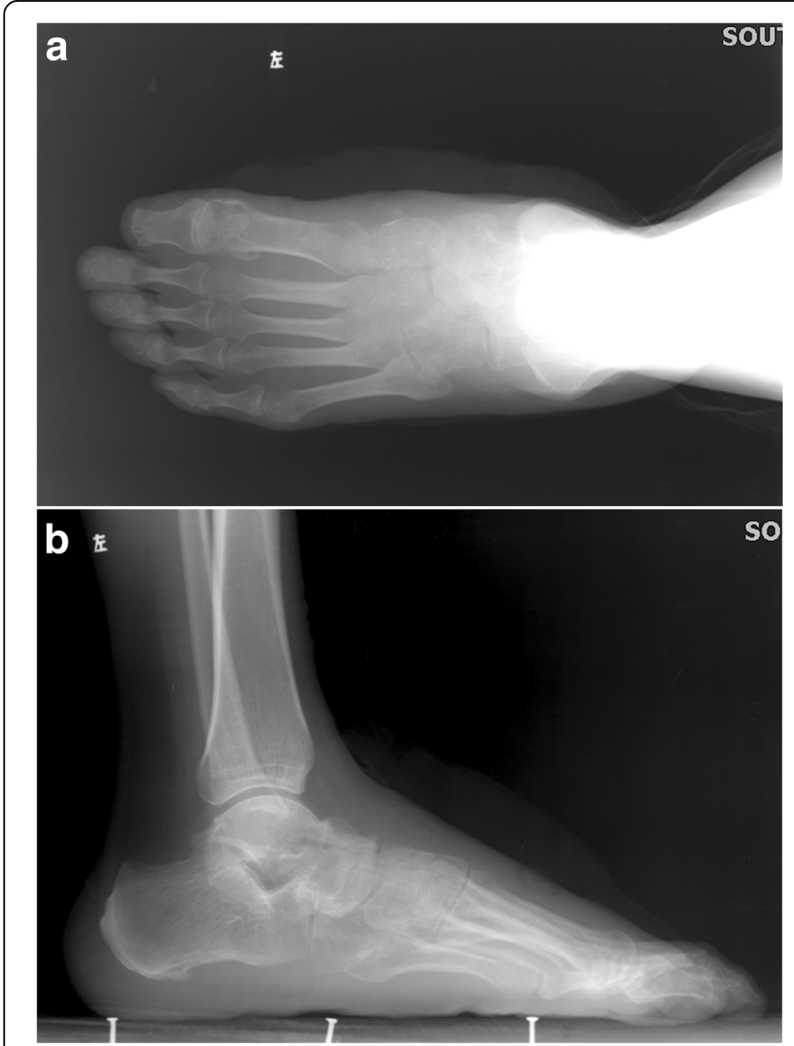

Fig. $\mathbf{6}$ a, b One year later after post operation the TN interfixations have been removed and the TN joint fused solidly

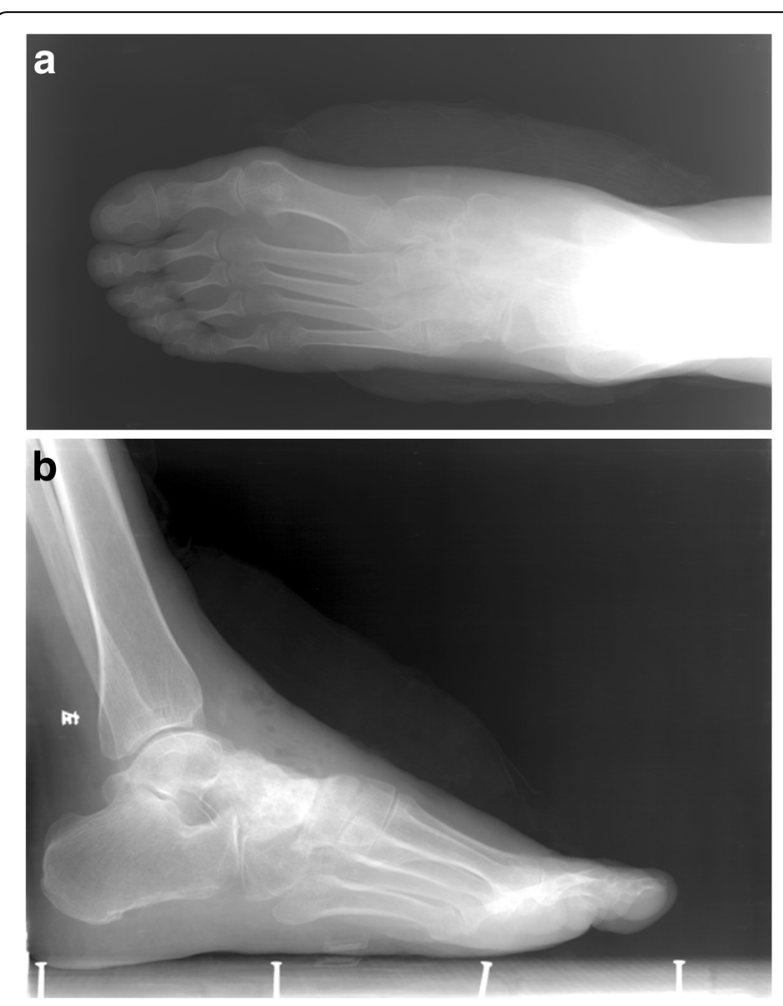

Fig. 7 a, b The TNC joint have good solid fused after removing the TNC interfixation

cuneiform (TNC) arthrodesis for the moderate MWD (stage III and IV) depending on the adjacent joints arthritic change by MRI scans. For the stage III or IV MWD disease, the isolated talonavicular arthrodesis is enough if the osteoarthrosis only exit in talonavicular joint. Talonavicular-cuneiform (TNC) arthrodesis is an advocated technique for the stage III MWD disease with alleviating the pain and excellent results in consolidation if osteoarthrosis in the joints around navicular. Reverse "V" shape osteotomy of the talonavicular joint can increase the medial longitudinal arch and avoid the secondary pain caused by flatfoot. We selected an allograft of tricortical iliac crest for reconstruction the excised navicular fragment [6].

The arthrodesis of peri-navicular could get the satisfaction clinic results. Lui [12] reported that of 6 patients with Müller-Weiss disease were treated with arthroscopic triple arthrodesis, at 43.5 months follow-up, the AOFAS ankle-hindfoot score increase 43.8 points (from 37.7 points preoperatively to 81.5 points postoperatively). CK Lu [11] reported that 13 feet of 13 patients with patients with Müller-Weiss disease with a mean age of 55.6 years were received the isolated talonavicular arthrodesis. The average modified American Orthopaedic Foot and Ankle Society (AOFAS) ankle-hindfoot score improved from 48.5 points preoperatively to 87.2 points at 
final follow-up (mean 51 months, range 10-114 months). Three cases were nonunion. In our study, either the isolated talonavicular arthrodesis or talonavicular-cuneiform (TNC) arthrodesis was gained the good clinic results and the solid fusion.

\section{Conclusions}

Throughout, the main limitation of the current study is the small number of cases; either TN or TNC arthrodesis for stage III or IV Müller-Weiss disease according to MRI evaluation have the good clinical outcomes with solid fusion rate and obvious improvement of the quality of life of patients. A large sample size and long-term clinical follow-up studies are required to evaluate the efficacy and safety of these methods.

\section{Acknowledgements}

We acknowledge the assistance of investigators and all subjects for participants in this study.

\section{Funding}

This study was supported by the Science Foundation of Southwest Hospital (No. SWH2016DCX1014).

\section{Availability of data and materials}

All data and materials were in full compliance with the journal's policy.

\begin{abstract}
Authors' contributions
All surgical procedures were carried out by K-LT. K-LT applied this study. H-HC participated in the patient selection, investigation on the outpatient clinic, and radiographic assessment, literature search, data monitoring, and manuscript writing. W-ZL carried out the statistical analysis. All authors have read and approved the final manuscript.
\end{abstract}

\section{Competing interests}

The authors declare that they have no competing interests.

\section{Consent for publication}

All patients enrolled into the study agree the use of patients' data for research.

\section{Ethics approval and consent to participate}

The study was approved by the Ethics Committee of the Southwest Hospital Affiliated with the Third Military Medical University. All patients eventually provided their informed consent at enrollment.

\section{Publisher's Note}

Springer Nature remains neutral with regard to jurisdictional claims in published maps and institutional affiliations.

\section{Author details}

'Department of Orthopaedic Surgery, Southwest Hospital, The Third Military Medical University, Gaotanyan Str. 30, Chongqing 400038, People's Republic of China. ${ }^{2}$ Department of Orthopaedic Surgery, The Traditional Medical Hospital of Chongaing, China, The Brach 4th Panxi Road, Jiangbei,

Chongqing 400021, People's Republic of China.

Received: 29 March 2017 Accepted: 21 May 2017

Published online: 05 June 2017

\section{References}

1. El-Karef E, Nairn D. The Müller-Weiss syndrome: spontaneous osteonecrosis of the tarsal navicular bone. Foot. 1999:9:153-5.

2. Reade B, Atlas G, Distazio J, Kruljac S. Müller -Weiss syndrome: an uncommon cause of midfoot pain. J Foot Ankle Surg. 1998;37(6):535-9.

3. Viladot A, Rochera R, Viladot Jr A. Necrosis of the navicular bone. Bull Hosp Joint Dis Orthop Inst. 1987;47(2):285-93.
4. Rochera R, Macule F, Diaz E, Sans JR. Aportacion al conocimiento de la escafoiditis tarsiana [An approach to the knowledge of tarsal scaphoiditis]. Chir del Piede. 1981;5(1):23-32.

5. Maceira E, Rochera R. Müller-Weiss disease: clinical and biomechanical features. Foot Ankle Clin N Am. 2004;9:105-25.

6. Cao HH, Tang KL, Xu JZ. Peri-navicular arthrodesis for the stage III Mu " Iler-Weiss disease. Foot Ankle Int. 2012;33(6):475-8.

7. Tosun B, Al F, Tosun A. Spontaneous osteonecrosis of the tarsal navicular in an adult: Mueller-Weiss syndrome. J Foot Ankle Surg. 2011;50:221-4.

8. Taimur M, Toby J, Dev D. Müller -Weiss disease- Review of current knowledge. Foot and Ankle Surgery. 2014;20:79-84.

9. Fernández de Retana P, Maceira E, Fernández-Valencia JA, Suso S. Arthrodesis of the talonavicular-cuneiform joints in Müller-Weiss disease. Foot Ankle Clin. 2004;9:65-72.

10. Zhang $\mathrm{H}$, Li J, Qiao Y, et al. Open triple fusion versus TNC arthrodesis in the treatment of Mueller-Weiss disease. J Orthop Surg Res. 2017;12(1):13. doi:10.1186/s13018-017-0513-3.

11. Lu CK, Fu YC, Cheng YM, Huang PJ. Isolated talonavicular arthrodesis for Müller-Weiss disease. Kaohsiung J Med Sci. 2014;30:471-6.

12. Lui TH. Arthroscopic triple arthrodesis in patients with Müller-Weiss disease. Foot Ankle Surg. 2009;15:119-22.
Submit your next manuscript to BioMed Central and we will help you at every step:

- We accept pre-submission inquiries

- Our selector tool helps you to find the most relevant journal

- We provide round the clock customer support

- Convenient online submission

- Thorough peer review

- Inclusion in PubMed and all major indexing services

- Maximum visibility for your research

Submit your manuscript at www.biomedcentral.com/submit
C Biomed Central 